\title{
Projeto Tarde Saborosa
}

\author{
Amadei, Carmelina; Barros, Maria do Socorro S. de; Scaramuzzi, Luciana Pierina; Marcos, \\ Jacqueline São; Marianetti, Alessandra Martins; Okamoto, Mercia
}

Centro de Referência da Saúde da Mulher — carmelinaamadei@yahoo.com.br

Introdução: As doenças crônicas são as principais causas de morte no mundo e o câncer tem se destacado por seu crescimento em todo o continente. nos casos em que o indivíduo recebe diagnóstico com a doença em estágio avançado, a Organização Mundial de Saúde descreve um modelo de atenção à saúde denominado cuidados paliativos, uma abordagem que melhora a qualidade de vida dos pacientes e familiares frente a problemas associados à doença terminal, através da prevenção, alívio do sofrimento, identificando, avaliando e tratando a dor e demais sintomas físicos, sociais, psicológicos e espirituais. Palliare significa amparar, transmitindo a perspectiva de cuidar e não somente curar. Humanização no atendimento se fundamenta no respeito e valorização da pessoa humana e constitui um processo que visa a transformação da cultura institucional, por meio da construção coletiva de compromissos éticos e de métodos para as ações de atenção à Saúde. Baseado no exposto, a nutrição tem papel essencial nos cuidados ao paciente oncológico. Dentre outros fatores a alimentação pode envolver afeto e carinho. o paciente com câncer avançado apresenta alteração metabólica importante podendo levar a anorexia e caquexia. a alimentação é um dos poucos meios de expressão do paciente, pois nela é transmitida a sua vontade. Identificar o simbolismo de comer leva a uma maior eficácia da terapêutica. Objetivos: oferecer satisfação gustativa e resgatar lembranças agradáveis aos pacientes em cuidados paliativos em prolongado período de internação; traçar estratégias para um tratamento nutricional adequado seguindo princípios da bioética, promovendo o seu bem estar. Métodos: elaborar cardápio diferenciado com preparações que tragam lembranças da infância e momentos especiais. Além do lanche é oferecida uma lembrança com mensagem de incentivo elaborada pelas nutricionistas, buscando colaborar na evolução favorável da inapetência, desinteresse pelos alimentos e recusa daqueles de maior preferência. para avaliar a satisfação e sugestão para próximas preparações é aplicado um questionário pelo nutricionista. Resultados parciais (julho a novembro de 2013). em relação a análise do consumo da preparação oferecida: $51,02 \%$ consumiram tudo, $16,32 \%$ consumiram metade, $22,44 \%$ consumiram menos da metade e $10,20 \%$ não consumiram nada. em relação ao sabor da preparação oferecida: $52,27 \%$ ótimo, 38,64\% bom e 6,82\% regular. em relação ao sentimento de receber uma preparação especial, $90 \%$ das pacientes relataram sentir-se feliz. Dentre as pacientes que sugeriram preparações, $87,50 \%$ preferiram preparações doces e 9,37\% preferiram preparações salgadas. Conclusões: Segundo a American Dietetic Association, a nutrição em pacientes com doença avançada, em cuidados paliativos deve oferecer: prazer, conforto emocional, auxiliando na diminuição da ansiedade e aumento da auto estima, além de permitir maior integridade e comunicação com seus familiares.

Amadei, Carmelina; Barros, Maria do Socorro S. de; Scaramuzzi, Luciana Pierina; Marcos, Jacqueline São; Marianetti, Alessandra Martins; Okamoto, Mercia. Projeto Tarde Saborosa. In: Anais do Congresso Internacional de Humanidades \& Humanização em Saúde [= Blucher Medical Proceedings, num.2, vol.1]. São Paulo: Editora Blucher, 2014. ISSN 2357-7282

DOI 10.5151/medpro-cihhs-10583 